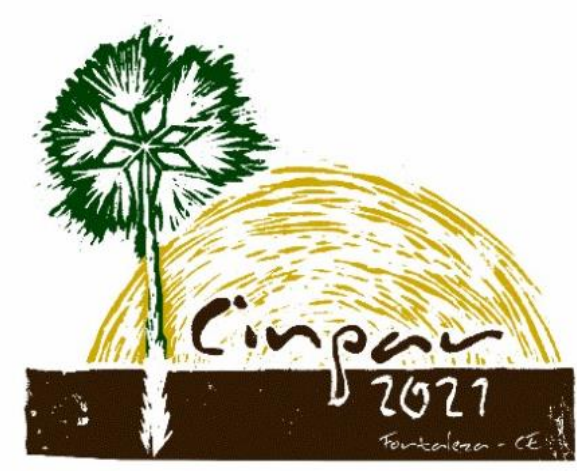

XVII Congresso Internacional sobre Patologia e Reabilitação das Construções

XVII Congreso Internacional sobre Patología y Rehabilitación de las Construcciones

XVII International Conference on Pathology and Constructions Rehabilitation

FORTALEZA (Brasil), 3 a 5 de junho de 2021

https://doi.org/10.4322/CINPAR.2021.057

\title{
Manifestações patológicas em revestimentos cerâmicos de fachadas: Um estudo de caso na central da biblioteca do Centro de Ciências e Tecnologia Agroalimentar. \\ Pathological manifestations in ceramic coatings of facades: a case study in the central library of the Center of Science and Agri-food Technology
}

\author{
Karinne Martins BATISTA ${ }^{1}$, Elisângela Pereira da SILVA², Arilson de Oliveira ARAUJO ${ }^{3}$ \\ ${ }^{1}$ Universidade Federal de Campina Grande, Pombal, Brasil, karinnemartins100@gmail.com \\ ${ }^{2}$ Universidade Federal de Campina Grande, Pombal, Brasil, elisangellapereira@yahoo.com.br \\ ${ }^{3}$ Universidade Federal de Campina Grande, Pombal, Brasil, arilson.araujors@gmail.com
}

Resumo: O revestimento cerâmico de fachada é bastante utilizado nas nossas edificações, atribuindo as mesmas, embelezamento e proteção. No entanto, esse revestimento apresenta diversas manifestações patológicas, oriundas de diversas causas e muitas vezes complexas. Assim, o presente artigo tem por objetivo analisar as principais manifestações patológicas inerentes aos revestimentos cerâmicos na central da biblioteca da Universidade Federal de Campina Grande, na cidade de Pombal-PB. O procedimento metodológico se baseou inicialmente na coleta de informações preliminares acerca da edificação. Sucessivamente, foi realizado uma inspeção visual no entorno, a fim de identificar, em primeiro plano, as manifestações nos revestimentos. Logo após, foi realizado o registro fotográfico, pois o levantamento fotográfico é de suma importância na fase da inspeção de campo, guardando as imagens para que, posteriormente, possa colaborar com as retiradas de possíveis dúvidas e/ou esclarecimentos. Por fim, foi realizado o ensaio a percussão em conformidade com a NBR 13755/2017 e faz-se os tratamentos dos dados através de tabelas e gráficos. Cabe mencionar que, as fachadas foram modeladas no software Revit, em virtude de auxiliar a visualização real das ocorrências com o intuito de facilitar à possível manutenção. Portanto, foi possível constatar que as três maiores incidências das manifestações patológicas no âmbito exposto, foram desplacamento cerâmico, descolamento e fissuras. Foi diagnosticado sua possível causa e sucessivamente, seu tratamento.

Palavras-chave: Manifestações Patologias, Inspeções, Incidências.

Abstract: The ceramic façade coating is widely used in our buildings, assigning them, beautification and protection. However, this coating presents several pathological manifestations, arising from various causes and often complex. Thus, this article aims to analyze the main pathological manifestations inherent to ceramic coatings in the central library of the Federal University of Campina Grande, in the city of Pombal-PB. The methodological procedure was initially based on the collection of preliminary information about the building. Subsequently, a visual inspection was carried out in the surroundings, in order to identify, in the foreground, the manifestations in the coatings. Soon after, the photographic record was made, because the photographic survey is of paramount importance in the field inspection phase, saving the images so that, later, it can collaborate with the removal of possible doubts and / or clarifications. Finally, the percussion test was performed in accordance with NBR 13755/2017 and the data were processed through tables and graphs. It is worth mentioning that the facades were modeled in Revit software, due to assisting the actual visualization of occurrences in order to facilitate possible maintenance. Therefore, it was possible to verify that the three highest incidences of pathological manifestations in the exposed scope were ceramic deplatement, detachment and fissures. Its possible cause was diagnosed and successively its treatment. 
Keywords: Pathologies, Inspections, Incidences.

\section{Introdução}

A fachada é a primeira coisa que olhamos quando nos aproximamos de uma edificação. Sendo responsável pela durabilidade e proteção da mesma. O Brasil possui condições climáticas favoráveis ao uso de revestimentos cerâmicos nas fachadas. O clima predominantemente tropical e chuvoso torna esta opção das mais interessantes, tanto pelo aspecto do desempenho como pela durabilidade (ROSCOE, 2008 e FIGUEREDO JUNIOR, 2017).

No Brasil, existe uma predileção pelo revetimento cerâmico aderido, isto pode ser devido as vantagens que este sistema apresenta, como por exemplo, a valorização estética, facilidade de limpeza; possibilidade estética variável e uma maior resistência a água.

Apesar de bastante utilizado, os revestimentos aderidos, apresentam muitas manifestações patológicas, com causas bastante variadas, que englobam desde a falta ou falha de projeto, desconhecimento dos materiais e técnicas corretas que devem ser utilizadas.

Segundo Zuchett (2016) as patologias mais relevantes desse sistema, surgem comumente na forma de fissuras e perda de aderência da argamassa de assentamento (descolamentos), em geral, ocasionados devido a ação das intempéries incidentes sobre o revestimento; além das deformações excessivas da estrutura e inadequação das camadas do revestimento. Essas patologias em quase sua totalidade, não são inerentes apenas de um fator, mas de um conjunto e/ou combinações dos mesmos, acarretando assim vários prejuízos para todos os envolvidos no processo construtivo, seja em impactos visuais na edificação ou, em casos mais graves, acidentes que podem conduzir a mortes. Os problemas de descolamentos em fachada, são críticos devido aos riscos de acidentes que oferecem na queda de placas ou de partes das camadas. (FIGUEREDO JÚNIOR, 2017).

A avaliação da qualidade do revestimento cerâmico aplicado em fachadas é de grande importância, uma vez que o mesmo está sujeito a um nível de exigências muito maior, por conta da exposição a elementos, como sol, vento, chuva e outros (SANTOS 2012; ZUCHETT, 2016; FIGUEIREDO JÚNIOR 20117).

O referido trabalho tem como objetivo a identificação das manifestações patológicas oriundas dos revestimentos das fachadas da biblioteca da Universidade Federal de Campina Grande (UFCG) campusPombal-PB. Para isso foi realizado registro fotográfico e ensaio de percusão segundo a NBR 13755/2017 em todas as fachadas da edificação. A vistoria in loco foi bastante útil para a caracterização das manifestações existentes e o ensaio de percusão foi fundamental para a determinação das áreas descoladas e desplacadas das fachadas.

\section{Metodologia}

A edificação estudada está localizada na cidade de Pombal - PB, no Centro de Ciências e Tecnologia Agroalimentar (CCTA) da Universidade Federal de Campina Grande (UFCG). A edificação possui fachadas revestidas parcialmente por revestimento cerâmico, com peças de dimensões $5 \times 20 \mathrm{~cm}$, que imitam tijolos aparentes. A biblioteca é um prédio de doze (12) anos e pode ser observada na Figura 1. 


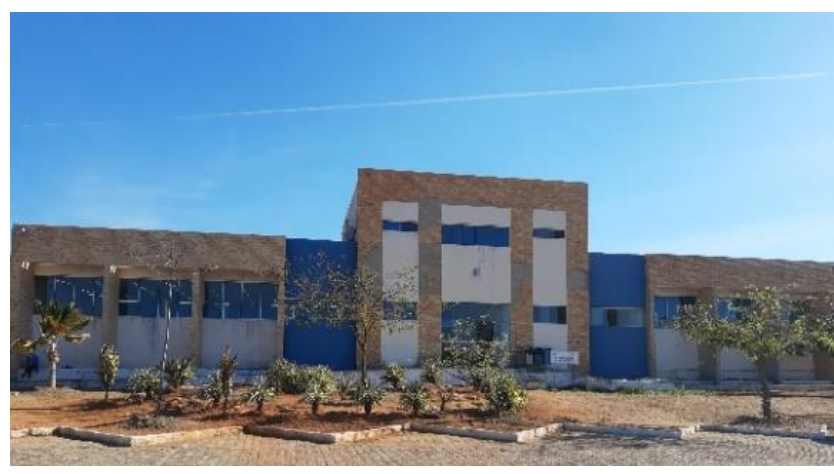

Figura 1 - Fachada norte da Central de biblioteca, Campus CCTA

Fonte: Autores, 2021

O trabalho foi dividido em etapas. Primeiramente foi analisado os projetos arquitetônicos da edificação; tendo sido os mesmos cedidos pela subprefeitura do campus. O projeto de arquitetura foi fornecido através de um arquivo DWG, elaborado no software AutoCAD, contendo as plantas baixas, de locação e coberta, cortes e as quatro fachadas. As plantas de fachada foram impressas para auxiliar no levantamento das áreas desplacadas e no ensaio de percussão. Vale mensionar que o prédio em estudo, durante sua existência (12 anos) nunca passou por nenhuma manutenção nas fachadas.

Em seguida foi realizada uma análise visual e registro fotográfico das fachadas norte, sul, leste e oeste, com uma câmera de smartphone Motorola One Vision, com câmera traseira de 48 MP Quad Pixel de resolução, para identificação das manifestações patológicas presentes.

Com as plantas impressas, passou-se para a etapa do ensaio de teste de percussão. $O$ ensaio foi realizado em toda extensão das fachadas, segundo a NBR 13755/2017, que especifica que o mesmo deve ser executada através de impactos leves, com um martelo específico para tal fim, de modo que não ocorra nenhum comprometimento da aderência do sistema de revestimento, e que não cause danos a peça cerâmica. As áreas afetadas foram anotadas nos projetos de fachadas impressas.

Após levantamento das áreas desplacadas e descoladas, as fachadas foram modeladas no software Revit 2019. Através dessa ferramenta pertencente ao BIM (Building Information Modeling) foi possível detalhar melhor as áreas descoladas e desplacadas. Essa etapa foi fundamental para um levantamento correto das áreas descoladas e desplacadas para serem utilizadas numa possível recuperação.

\section{Resultados}

Através das etapas de análise visual e registo fotográfico, foi possível identificar, logo de início, a manifestação patológica predominante nas fachadas: o desplacamento dos revestimentos cerâmicos. Tal problema destaca-se frente ao demais, sobretudo nas fachadas leste e norte, como pode ser demonstrado através da Figura 2. A possível causa dessa anomalia, pode estar ligado ao fato dessas duas fachadas, leste e norte, sofrerem maior incidência solar ao longo do dia, o que pode ocasionar excessiva absorção de calor por parte dos revestimento; além disso, as diversas camadas: substrato, camada de regularização, argamassa colante e peça cerâmica sofrem dilatação termica diferente, podendo haver formações de tensões diferentes, o que causa primeiramente o desprendimento do revestimento e depois o desplacamento. 


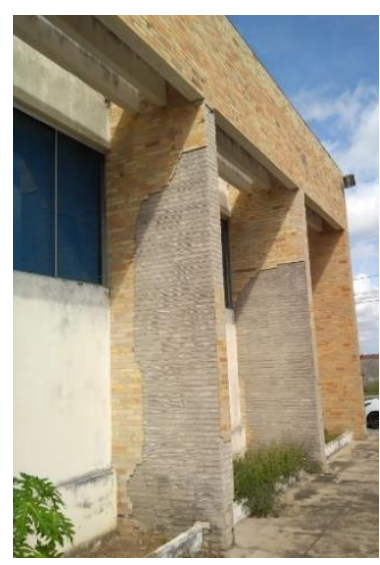

Figura 2 - Anomalia do desplacamento na fachada norte da edificação

Fonte: Autores, 2021

Ainda através do registro fotográfico, ao se aproximar das áreas afetadas, notou-se que ao longo de toda a extensão de cada uma delas, há a presença de cordões de argamassa intactos, como pode ser observado na Figura 3.

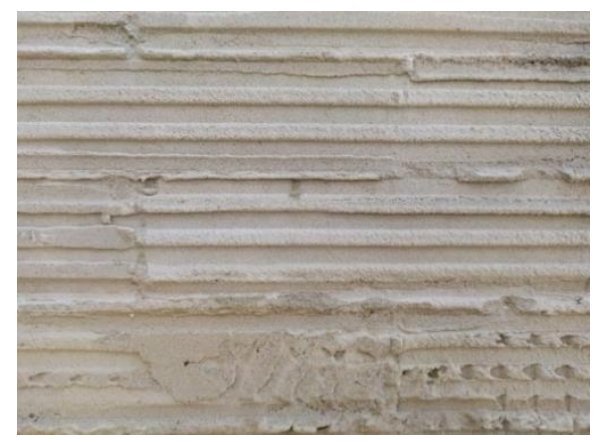

Figura 3 - Cordões de argamassa de assentamento na superfície da fachada

Fonte: Autores, 2021

Este fato, demonstra que os cordões não foram quebrados no momento de assentamento das peças, demonstrando o não seguimento das especificações apresentadas pela NBR 13755:2017 - "Revestimentos Cerâmicos De Fachadas E Paredes Externas Com Utilização De Argamassa Colante". Além disso, ao analisar as peças cerâmicas desplacadas, ficou evidente que houve uma perda de aderência entre a mesma e a argamassa de assentamento, pois as peças analisadas desplacam com o tardoz limpo; demonstrado na Figura 4.

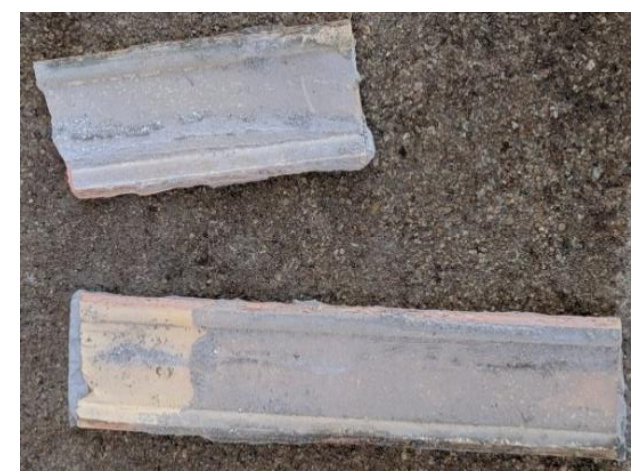

Figura 4 - Peça do revestimento cerâmico de fachada desplacada, mostrando a não aderência da argamassa

Fonte: Autores, 2021

Manifestações patológicas em revestimentos cerâmicos de fachadas: Um estudo de caso na central da biblioteca do Centro de Ciências e Tecnologia Agroalimentar 
A situação apresentada nas figuras 3 e 4 observadas em todas as fachadas pode estar interligadas à três fatores. O primeiro, é que as peças cerâmicas possuem o tardoz limpo, sem rugosidade, o que pode prejudicar a aderência com a argamassa. O segundo fator que pode ter ocorrido, é que a argamassa utilizada na aplicação não era própria para revestimentos externos, que conforme a NBR 13755/2017, deve ser do tipo AC III, própria para fachadas, por resistir melhor a ação de intempéries como calor, umidade, entre outros e o terceiro fator diz respeito a erro durante a execução, pois os cordões não quebrados (Figura 3) indica que a peça não sofreu compressão suficiente.

As fachadas modeladas no software Revit 2019, estão representadas nas Figuras 5,6, 7 e 8. Sendo a coloração avermelhada indício de peça cerâmica descolada e a cor cinza representa a parte desplacada.

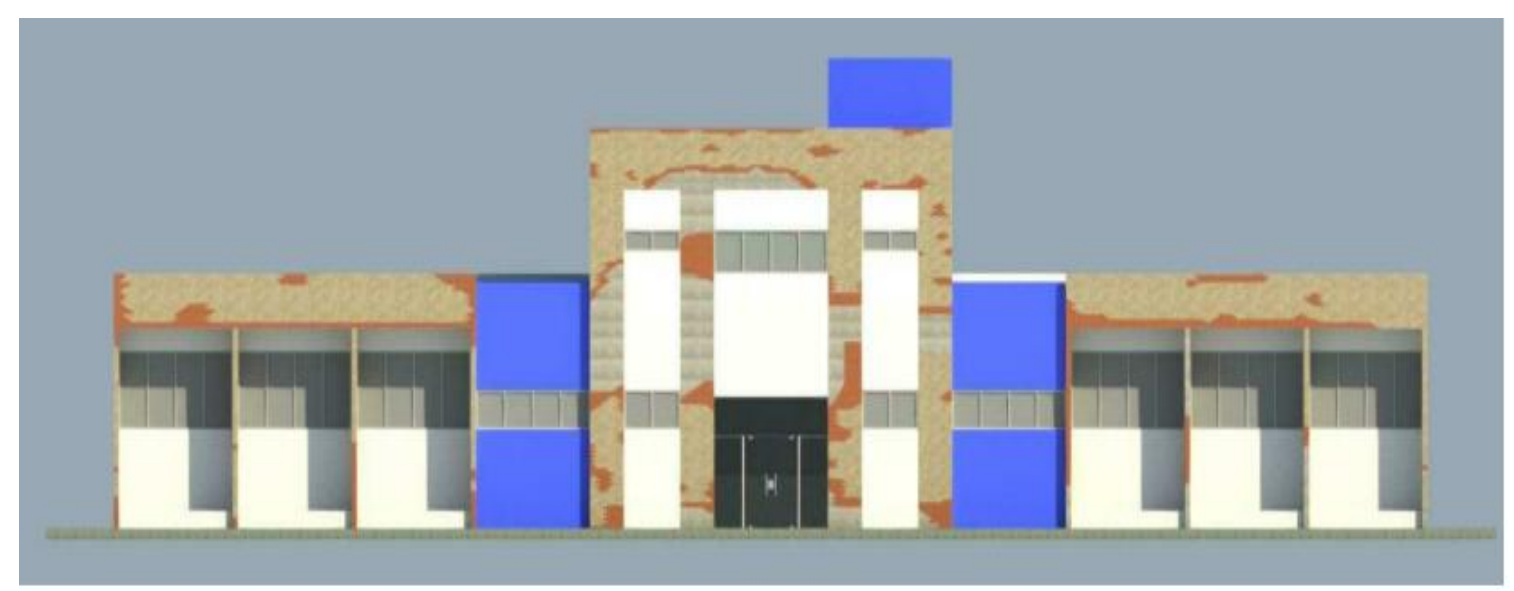

Figura 5 - Fachada norte com revestimento cerâmico já desplacado (em cinza) e descolado (em vermelho)

Fonte: Autores, 2021

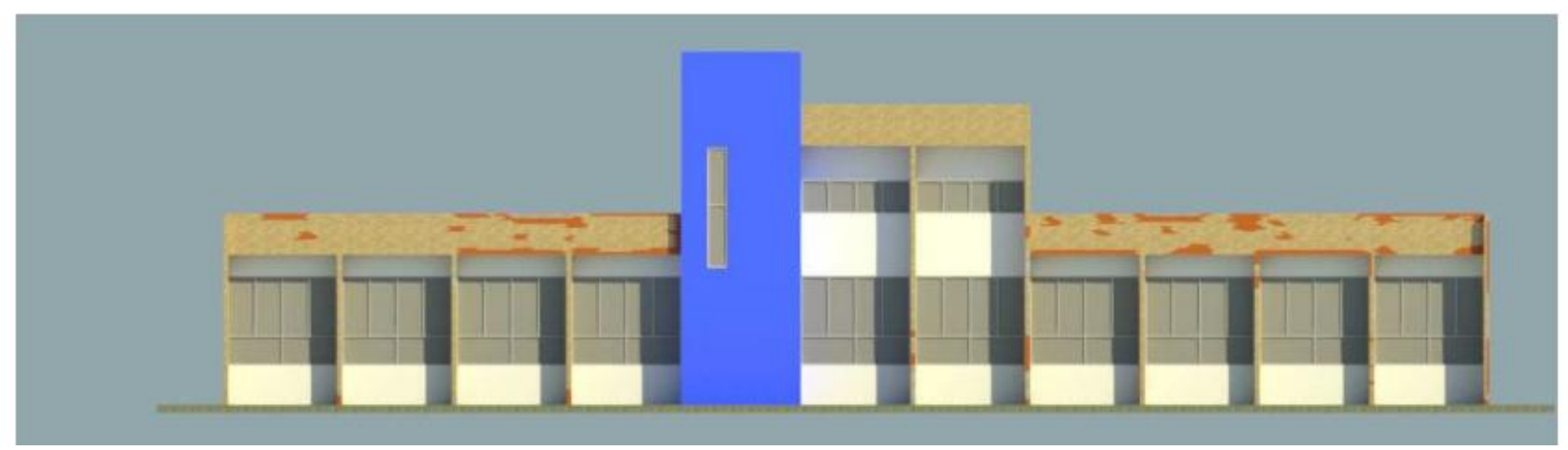

Figura 6 - Fachada sul com revestimento cerâmico já desplacado (em cinza) e descolado (em vermelho)

Fonte: Autores, 2021 


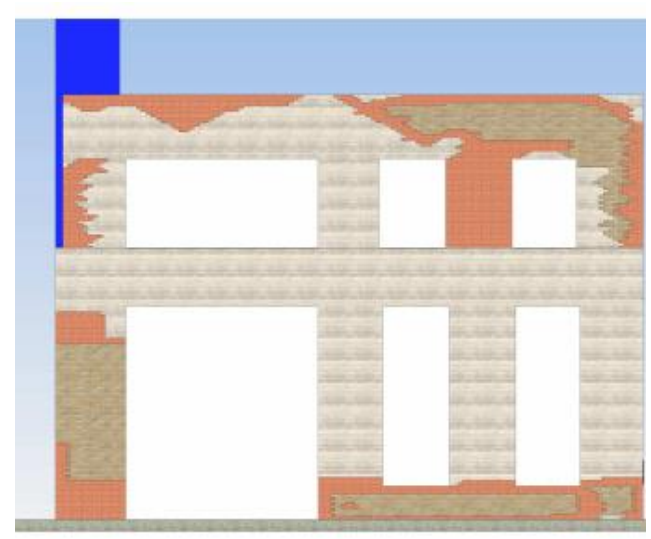

Figura 7 - Fachada leste com revestimento cerâmico já desplacado (em cinza) e descolado (em vermelho)

Fonte: Autores, 2021

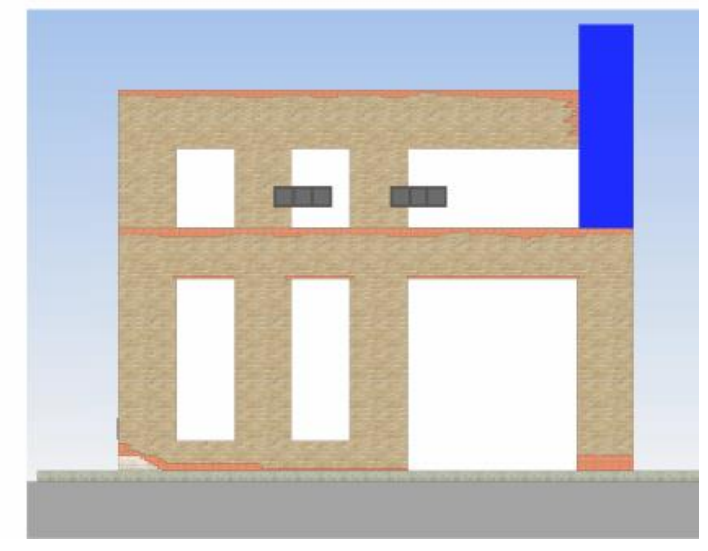

Figura 8 - Fachada oeste com revestimento cerâmico já desplacado (em cinza) e descolado (em vermelho)

Fonte: Autores, 2021

Por meio dos quantitativos fornecidos pelo próprio programa Revit 2019, obteve-se às áreas totais das manifestações patológicas descolamento e desplacamento para cada fachada, apresentados no Quadro 1.

Quadro 1 - Dados informativos da edificação

\begin{tabular}{cccc}
\hline \multirow{2}{*}{$\begin{array}{c}\text { Orientação das } \\
\text { fachadas }\end{array}$} & $\begin{array}{c}\text { Área total de } \\
\text { revestimento } \\
\text { cerâmico das } \\
\text { fachadas }\end{array}$ & $\begin{array}{c}\text { Aesplacamento } \\
\text { cerâmico }\end{array}$ & $\begin{array}{c}\text { Destacamento } \\
\text { cerâmico }\end{array}$ \\
\hline Norte & 258,04 & 21,07 & 31,1 \\
Sul & 303,12 & 4,09 & 13,57 \\
Leste & 121,93 & 55,05 & 15,37 \\
Oeste & 121,95 & 0,97 & 6,08 \\
Total & 805,04 & 81,18 & 66,12 \\
\hline
\end{tabular}

Fonte: Autores, 2021

As fachadas do referido prédio apresentaram área total de desplacamento de $81,18 \mathrm{~m}^{2}$, e área total de descolamento de $66,12 \mathrm{~m}^{2}$. A fachada leste é a que apresenta maior área desplacada, com 55,05 $\mathrm{m}^{2}$, seguida pela fachada norte com 21,07 $\mathrm{m}^{2}$ de área. Enquanto o descolamento é mais evidente na fachada norte com 
$31,1 \mathrm{~m}^{2}$, seguido da fachada leste com $15,37 \mathrm{~m}^{2}$ de área. Através desses quantitativos, é possível afirmar que a quantidade total de revestimento cerâmico necessário para se realizar a manutenção e reparação de todas as quatro fachadas da edificação é de $147,30 \mathrm{~m}^{2}$.

Além das manifestações patológicas citadas, também foi verificado a incidência de fissuras na junta de assentamento e eflorescência. Na figura 9 é observado fissuras na junta de assentamento. Segundo Figueiredo Junior (2017) a deterioração das juntas compromte o desempenho de todo o revestimento cerâmico, pois essas são responsáveis pela estanqueidade do revestimento e pela capacidade de absorver deformações. Além disso, a agressividade do ambiente e as solicitações devido à movimentações diferenciais também podem comprometer a integridade das juntas, gerando fissuras ou trincas, que podem causar descolamento dos revestimentos e progredir para o desplacamento.

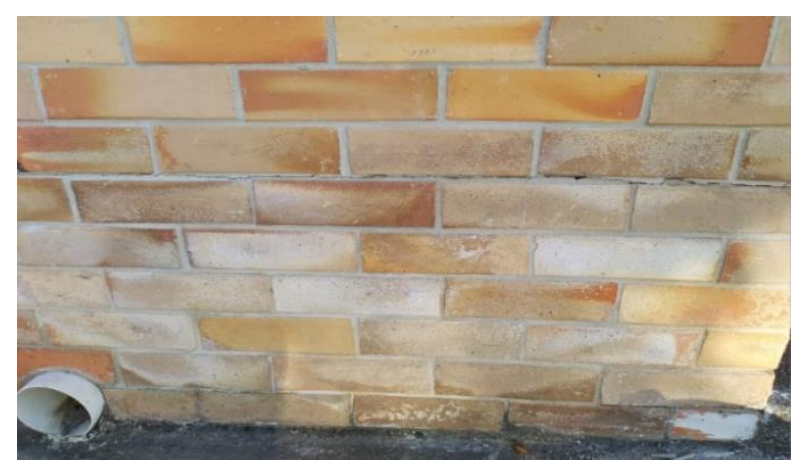

Figura 9 - Fissuras no rejuntamento entre as peças cerâmicas na fachada norte

Fonte: Autores, 2021

As eflorescências surgem com o aparecimento de manchas brancas e são decorrentes de reações químicas que acontecem quando alguns materiais que são utilizados para o assentamento das placas possuem alto teor de hidróxido de sódio, conforme explicitações de Bauer et al. (2007). Desse modo, quando esse hidróxido entra em contato com a água, é dissolvido. Assim, quando a água evapora, esse componente vai para a superfície do material, à qual reage com o dióxido de carbono presente no ar, ocasionando assim, as manchas. A eflorescência observada na figura 10, pode ter como causa a própria cerâmica utilizada, que pode ter um alto teor de sais solúveis, ou até mesmo falha durante o preparo da argamassa; a mesma pode ter sido preparada com excesso de água, além da alta temperatura presente na região, cuja mesma pode acelerar tais reações químicas. Segundo Fontinelle e Moura (2004) não haverá ocorrência deste problema, quando eliminado qualquer um desses fatores: sais solúveis, presença de água ou porosidade do componente do revestimento. Ainda segundo os mesmos autores, para a remoção dos depósitos nas áreas comprometidas com este problema, pode-se recorrer a uma simples lavagem da superfície do revestimento, mas, o problema pode retornar principalmente se as condições continuarem a serem propícias.

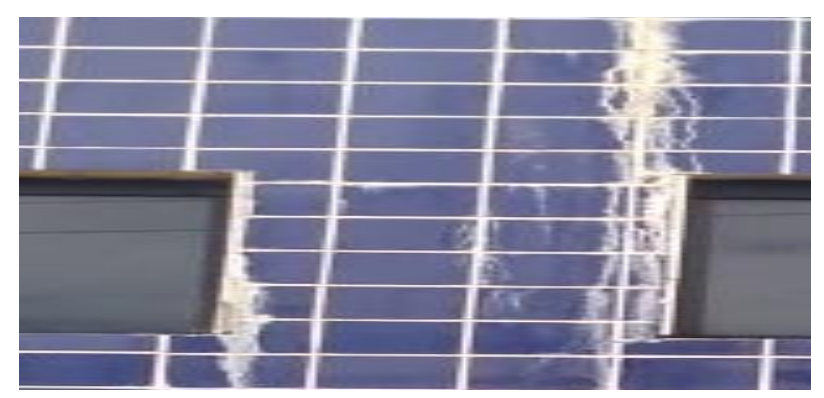

Figura 10 - Eflorescência aparente no revestimento cerâmico da fachada norte

Fonte: Autores, 2021 


\section{Conclusões}

As manifestações patológicas encontradas nas fachadas foram descolamento, desplacamento, fissuras na juntas de assentamento e eflorescência. A representação das fachadas no software Revit 2019 juntamente com o teste de percusão possibilitou o levantamento exato das áreas com manifestações patológicas de descolamento e desplacamento, sendo mais evidente essas manifestações nas fachadas norte e leste. Este dado será importante para uma recuperação futura das fachadas. As manifestações patológicas fissuras foram encontradas em todas as fachadas e a eflorescência apenas na fachada norte. As fissuras se não sanadas podem evoluir para um desplacameno do revestimento; elas também constituem de caminho para entrada de água e surgimento da eflorescência. A falta de manutenção contribuiu para o surgimento das manifestações patológicas citadas.

\section{Agradecimentos}

Os autores agradecem ao Centro de Ciências e Tecnologia Agroalimentar por todo apoio e facilitação da logística para a realização do referido trabalho, em especial à Subprefeitura e aos servidores públicos do Centro.

\section{Referências Bibliográficas}

ASSOCIAÇÃO BRASILEIRA DE NORMAS TÉCNICAS - NBR 13755: Revestimento de paredes externas e fachadas com placas cerâmicas e com utilização de argamassa colante - Procedimento. Rio de Janeiro, 2017.

BAUER, R. J. F. Falhas em revestimentos. In: BAUER, L. A. F. (Coord.). Materiais de construção 2. 5ed . Rio de Janeiro: LTX, 1994. p. 887-929.

DE FIGUEIREDO JUNIOR, Geraldo Josafá. Patologias em revestimentos de fachadas-diagnóstico, prevenção e causas: Diagnóstico; prevenção e causas. 2017.

FONTENELLE, Ma Aridenise; MOURA, Yolanda. Montenegro. Revestimento Cerâmico em Fachadas Estudo das Causas das Patologias - Relatório da Pesquisa. Fortaleza, 2004.

ROSCOE, T. M. Patologias em Revestimentos Cerâmicos de Fachadas. 2008. 81 f Dissertação (Monografia apresentada ao Curso de Especialização em Construção Civil da Escola de Engenharia da UFMG). Universidade Federal de Minas Gerais 2008.

SANTOS, Daniel Carvalho dos. Revestimentos em Fachadas: Texturas x Cerâmicas. 2012. 112 f. Monografia (Especialização) - Curso de Curso de Especialização em Construção Civil, Departamento de Engenharia de Materiais e Construção, Universidade Federal de Minas Gerais, Belo Horizonte, 2012. Disponível em: $<$ http://www.bibliotecadigital.ufmg.br/dspace/bitstream/handle/1843/BUOS-

9AHG9S/monografia__daniel_carvalho_dos_santos.pdf?sequence=1>. Acesso em: 18 dez. 2020.

SILVA, M. N. B. Avaliação quantitativa da degradação e vida útil de revestimentos de fachada - aplicação ao caso de Brasília/DF. Tese (Doutorado) Universidade de Brasilia, 2014.

ZUCHETTI, Pedro Augusto Bastiani. Patologias da construção civil: investigação patológica em edifício corporativo de administração pública no Vale do Taquari/RS. 2016. Trabalho de Conclusão de Curso. 